\title{
Cross-Cultural Adaptation and Validation of the Arabic Version of the Intermittent and Constant Osteoarthritis Pain Questionnaire
}

(ㅇ) (1) $(\odot)$

\author{
Authors \\ Musab Alageel'1, Abdullah Al Turki², Ali Alhandi², Rawa Alohali', Rakan Alsalem¹, Sami Aleissa²
}

\author{
Affiliations \\ 1 King Saud University College of Medicine, Riyadh, \\ Saudi Arabia \\ 2 King Abdulaziz Medical City, Orthopeadic, Riyadh, \\ Saudi Arabia
}

\section{Key words}

spine, knee, Osteoarthritis, sports performance, cardiovascular physiology, exercise, anabolic steroids, ischemic preconditioning, sport recovery, copy editing, Ger > Eng translation, Medicine, Knee, Pain, Hib, Validation, sportsmedicine, international open, journal

$\begin{array}{ll}\text { received } & 08.07 .2019 \\ \text { revised } & 05.10 .2019 \\ \text { accepted } & 09.10 .2019\end{array}$

Bibliography

DOI https://doi.org/10.1055/a-1031-0947

Sports Medicine International Open 2019; 3: E8-E12

(c) Georg Thieme Verlag KG Stuttgart · New York

ISSN 2367-1890

\section{Correspondence}

Dr. Sami Aleissa

Orthopeadic,

King Abdulaziz Medical City,

Riyadh

11426

Saudi Arabia

Tel : 966-1-801-1111- 15485, Fax : 966-1-801-1111- 15485

saleissa@yahoo.com

\begin{abstract}
This study aimed to translate and adapt the Intermittent and Constant Osteoarthritis Pain questionnaire into the Arabic language and evaluate the validity and reliability of this scale for participants with knee or hip osteoarthritis. This questionnaire was translated based on the Manufacturers Alliance for Productivity and Innovation protocol. The test-retest reliability was calculated using the Intraclass Correlation Coefficient. Then, Cronbach's alpha was used to assess the internal consistency of Intermittent and Constant Osteoarthritis Pain questionnaire. After that, the criterion validity was evaluated against the Knee injury and Osteoarthritis Outcome Score. A total of 90 participants were included in this study, of which 29 participants were re-evaluated for reliability testing. The Intraclass Correlation Coefficient of the Knee Intermittent and Constant Osteoarthritis Pain questionnaire were $0.841,0.923$ and 0.911 for the total, constant, and intermittent knee pain, respectively. Cronbach's alpha was $0.88,0.93$ and 0.94 for the total score, the intermittent knee pain and the constant knee pain, respectively. Eventually, criterion validity was $r=0.24(P<0.05)$. Intermittent and Constant Osteoarthritis Pain in Arabic is a valid and reliable instrument to be used in Arabic-speaking patients with knee/hip osteoarthritis.
\end{abstract}

\section{Introduction}

Osteoarthritis is mainly characterized as joint pain that interferes with a patient's life [1]. The knee, hip, and hand joints can be affected, and the knee is the most common [2]. Osteoarthritis is one of the most common forms of arthritis [3]. This disease has multifactorial causes, such as aging, the female gender, being overweight, and previous injury [4-7].

There are many approaches to diagnose osteoarthritis and determine the severity of the disease. The disease can be diagnosed clinically based on the presence of certain symptoms (pain, joint stiffness in the morning, and a decrease in the joint function), the above-mentioned risk factors, or radiographic images [8].

The extent of joint pain can be assessed by several questionnaires, and one of the most accurate is the Intermittent and Constant Osteoarthritis Pain (ICOAP) questionnaire, which was developed in focus groups to evaluate the severity of pain and its impact on the quality of life of patients with knee/hip osteoarthritis. Furthermore, it is the only scale that can evaluate the constant and intermittent pain that may present itself in patients with osteoarthritis. It can also 
be used to follow the progression of the disease, treatment responsiveness, and the need for joint replacements [13].

As the ICOAP questionnaire shows a high level of reliability for evaluating the patient's condition [9], it has been translated into several languages and is used in many studies within different populations $[10,11]$. This study aims to translate the scale into Arabic and validate it within the Saudi population.

\section{Methods}

The study was conducted in the orthopedic surgery clinic covering the period from March 2018 to August 2018. The study included any adult males or females who could speak, read, and write Arabic. Patients needed to be diagnosed with knee or hip osteoarthritis based on the clinical and radiographic criteria of the American College of Rheumatology (grade 2 or above according to the Kellgren-Lawrence classification system).

The study was conducted in two stages. The first stage was the translation of the scale into Arabic, and the second stage was data collection.

The scale was translated into Arabic following clear and userfriendly guidelines by an independent orthopedic resident and an
English teacher whose native language was Arabic. Both were fluent in English and Arabic, well-experienced in the cultures of the two languages, and had background knowledge of medical terms. We then compared and reviewed the two translated versions, after which the final version was adopted. Two backward translations of the new Arabic version to English were done by another two translators, who were native English speakers and were fluent in both languages. Sufficient knowledge of both cultures and languages and experience in translating medical studies were important criteria for selecting the translators. Finally, we compared and reviewed the two backward translations and then compared them again with the original instrument, obtaining the final ICOAP scale that was to be used in the study. After that, a pilot study was conducted with 30 participants who met the inclusion criteria to identify any difficulties in understanding the scale. Any notes or suggestions were taken into account prior to proceeding with the data collection.

After the validation process, here is the Intermittent and Constant Osteoarthritis Pain in Arabic (ICOAP-AR) questionnaire.

Knee ICOAP questionnaire:

Knee ICOAP questionnaire:

\begin{tabular}{|c|c|c|c|c|c|c|}
\hline لا لا يحتمل & شديد & 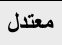 & طفيف & لا يوجد & 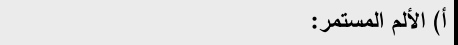 & \\
\hline & & & & & |المستمر إلأسبوع الماضي، ما ددى شدة ألم الركبة & 1 \\
\hline & & & & & |خلى نومك؟ الأسبوع الماضي، كيف أثر ألم الركبة المستمر & r \\
\hline & & & & & على الجودة العامة الماضي، كيف أثر ألم الركبة المستمر & r \\
\hline & & & & & بسبب الألم المستمر للركبة؟ ما مدى إحباطك أو إزعاجك & $\varepsilon$ \\
\hline & & & & & 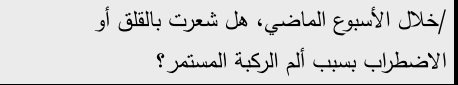 & 0 \\
\hline \multirow[t]{7}{*}{ ل الا يحتمل } & شديد & 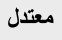 & طفيف & لا يوجد & ب) الألم المتقطع : & \\
\hline & & & & & المنقطع الأسبوع الماضي، ما مدى شدة ألم الركبة & 1 \\
\hline & & & & & /خلال الأسبوع الماضي، كم مرة شعرت بألم في ركبتك؟ & r \\
\hline & & & & & على نومك؟ الأسبوع الماضي، كيف أثر ألم الركبة المتقطع & $r$ \\
\hline & & & & & على الجودة العامة لحياتكي؟ الأسبوع الماضيف أثر ألم الركبة المتقطع & $\varepsilon$ \\
\hline & & & & & بسبب آلام الركبة المنقطعة؟ الأسبوع ما مدى إحباطك أو إزعاجك & 。 \\
\hline & & & & & خبلا الأسبوع الماضي، هل شعرت بالقلق أو الاضطراب & 7 \\
\hline
\end{tabular}


Hip ICOAP questionnaire:

Hip ICOAP questionnaire:

\begin{tabular}{|c|c|c|c|c|c|c|}
\hline لا يحتمل & شديد & معتدل & طفيف & لا يوجد & | أ) الألم المستمر: & \\
\hline & & & & & المستمر؟ الأسبوع الماضي، ما مدى شدة ألم الورك & 1 \\
\hline & & & & & على نومك؟ الأسبوع الماضي، كيف أثر ألم الورك المستمر & r \\
\hline & & & & & على الجودة العامة لحياتكي؟ الأسبوع الماضي أثر ألم الورك المستمر & $r$ \\
\hline & & & & & بسبب ألم الأورك المستمر الماضي، ما مدى إحباطك أو إزعاجك & $\varepsilon$ \\
\hline & & & & & 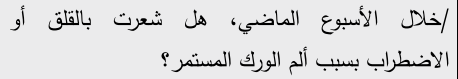 & 0 \\
\hline لا يحتمل & شديد & معتدل & طفيف & لا يوجد & ب) الألم المتقطع : & \\
\hline & & & & & المنظل الأسبوع الماضي، ما مدى شدة ألم الورك & 1 \\
\hline & & & & & /خلال الأسبوع الماضي، كم مرة شعرت بألم في الورك؟ & r \\
\hline & & & & & /خلال الأسبوع الماضي، كيف أثر ألم الورك المتقطع & $r$ \\
\hline & & & & & |خلى الجودة العامة لحباتكي؟ كيف أثر ألم الورك المنقطع & $\varepsilon$ \\
\hline & & & & & بسبب آلام الورك المنتطعةب؛ ما مدى إحباطك أو إزعاجك & ${ }^{\circ}$ \\
\hline & & & & & الاضطراب بسبب آلام الورك المتقطعة هل شعرت بالقلق أو & 4 \\
\hline
\end{tabular}

The second part of the study involved collecting data from the participants by distributing paper ICOAP questionnaires over two time intervals to ensure the reliability of the questionnaire. In the first round, we obtained the participants' approval by asking them to sign the consent form. During the second round, the participants answered two questionnaires. The first one was the ICOAP and the second questionnaire was the Knee injury and Osteoarthritis Outcome Score (KOOS) for constructive validity.

This study was conducted according to the ethical standards of the International Journal of Sports Medicine and was approved by the University ethics committee. A consent form was distributed and signed by each participant recruited in this study [18].

\section{Statistical analysis}

The data were analyzed using the Statistical Package for Social Studies (IBM SPSS Statistics for Windows, Version 22.0; IBM Corp., Armonk, NY, USA). The categorical variables were expressed as percentages. The continuous variables were expressed as mean \pm standard deviation.

Cronbach's alpha was used to assess the internal consistency of the ICOAP. The subscales to total and the inter-subscale correlations were used to assess the internal consistency with Pearson's correlation analysis. The test-retest values of the subscales and total scores were compared with the Wilcoxon signed-rank test. The test-retest reliability was calculated using the intraclass correlation coefficient (ICC). A p-value of $<0.05$ was considered statistically significant.

\section{Results}

A total of 90 subjects were included in this study, of which 29 participants were re-evaluated for reliability testing. The participants filled in all the sections of the ICOAP and the KOOS subscale. The demographic data is shown in $>$ Table 1.

Based on the participants' feedback, it was found that the translated definitions of both the terms 'Constant' and 'Intermittent' pain were clear, and the participants reported no difficulties in understanding the meaning of these two terms. Moreover, all the questions and answers were comprehensible.

As shown in > Table 2, the test-retest values of the subsample with 29 participants revealed no difference regarding the constant and transient knee pain and the constant and transient hip pain (p-value > 0.05). 
The ICC was used to assess test-retest reliability. The ICC of the total score of the knee ICOAP was 0.841 , and the score was 0.911 for the intermittent knee pain subscale and 0.923 for the constant knee pain subscale. Moreover, the ICC for the total score of the hip ICOAP was 0.923 , and the score was 0.950 for the intermittent hip pain subscale and 0.980 for the constant hip pain subscale.

Cronbach's alpha was $0.88,0.93$, and 0.94 for the total score, intermittent knee pain, and constant knee pain, respectively. Additionally, Cronbach's alpha of the hip ICOAP was 0.977, 0.963, and 0.985 for the total score, intermittent hip pain, and constant hip pain, respectively.

The correlation between the total score of the ICOAP and the KOOS pain subscale was assessed using the criterion validity, and

- Table 1 Demographic characteristics.

\begin{tabular}{|c|c|c|c|}
\hline & & Number & $\%$ \\
\hline \multirow[t]{2}{*}{ Gender } & Male & 44 & 48.9 \\
\hline & Female & 46 & 51.1 \\
\hline \multirow{5}{*}{$\begin{array}{l}\text { Monthly } \\
\text { Income }\end{array}$} & $<1333.4$ USD & 44 & 48.9 \\
\hline & 1333.4-2666.6 USD & 23 & 25.6 \\
\hline & 2666.6-4000 USD & 8 & 8.9 \\
\hline & 4000-5333.3 USD & 8 & 8.9 \\
\hline & > 5333.3 USD & 7 & 7.8 \\
\hline \multirow{5}{*}{$\begin{array}{l}\text { Level of Edu- } \\
\text { cation }\end{array}$} & Primary & 38 & 42.2 \\
\hline & Intermediate or Secondary & 29 & 32.2 \\
\hline & Bachelor & 15 & 16.7 \\
\hline & Diploma & 5 & 5.6 \\
\hline & Postgraduate & 3 & 3.3 \\
\hline \multirow{4}{*}{$\begin{array}{l}\text { Marital } \\
\text { Status }\end{array}$} & Single & 2 & 2.2 \\
\hline & Married & 77 & 85.6 \\
\hline & Divorced & 2 & 2.2 \\
\hline & Widowed & 9 & 10.0 \\
\hline
\end{tabular}

the results revealed that $r=0.235(P<0.05)$. Thus, based on the criterion validity, there is a correlation between the ICOAP and the KOOS pain subscale.

\section{Discussion}

Pain severity varies depending on the progression of the specific case [12]. Constant pain is less intense and is persistent all the time, whereas intermittent pain is more intense and transient. The ICOAP scale can measure the frequency and severity of the pain and its effect on mood, sleep, and the quality of life [9].

The results of this study revealed that the ICOAP-AR is valid and reliable for diagnosing patients with knee or hip osteoarthritis. No additional adjustments were made to the ICOAP items, which indicates the clarity of the scale when translated into Arabic.

Regarding the translation procedure and the cross-cultural adaptation, the translators faced no difficulties in translating and adapting the items and answers of the ICOAP into Arabic, which resulted in a comprehensible Arabic scale. This is also similar to other adaptation studies [13].

Furthermore, the majority of the participants faced no difficulty in answering the questionnaire, which mirrors other cross-cultural translations and adaptation studies $[10,11]$.

The ICOAP-AR scale was evaluated using the internal consistency and the test-retest reliability to identify the validity of this scale.

Cronbach's alpha of the total score for the Arabic knee ICOAPAR was 0.88 , which is close to the Persian study (0.89), the Portuguese study (0.92), and the original study that developed the ICOAP (0.93). Additionally, Cronbach's alpha of the total score for the hip ICOAP-AR was 0.97 , which is similar to the 0.93 value in the original study $[9,14,15]$.

The test and retest reliability was evaluated by giving the 29 participants the ICOAP scale two times, with a one-week period in between. The results were evaluated using the ICC, which was 0.841 .

> Table 2 The reliability and validity of the intermittent and constant osteoarthritis pain scale (ICOAP).

\begin{tabular}{|c|c|c|c|c|c|c|}
\hline \multicolumn{7}{|l|}{ Reliability } \\
\hline & \multicolumn{2}{|c|}{ Test $(n=90)$} & \multicolumn{2}{|c|}{ Retest $(n=29)$} & \multirow{2}{*}{$\begin{array}{l}\text { ICC } \\
\text { ( } 95 \% \text { confidence interval) }\end{array}$} & \multirow{2}{*}{$\begin{array}{l}\text { Alpha } \\
\text { coefficient }\end{array}$} \\
\hline & Mean & SD & Mean & SD & & \\
\hline \multicolumn{7}{|l|}{ ICOAP } \\
\hline \multicolumn{7}{|l|}{ Knee } \\
\hline Total score & 27.98 & 21.68 & 23.82 & 13.51 & $0.881(0.841-0.914)$ & 0.881 \\
\hline Constant pain subscale & 28.17 & 29.79 & 32.76 & 31.81 & $0.944(0.923-0.960)$ & 0.944 \\
\hline Intermittent pain subscale & 27.82 & 27.21 & 16.38 & 22.82 & $0.934(0.911-0.953)$ & 0.934 \\
\hline \multicolumn{7}{|l|}{ Hip } \\
\hline Total score & 9.97 & 21.97 & 3.45 & 9.16 & $0.977(0.969-0.983)$ & 0.977 \\
\hline Constant pain subscale & 9.94 & 23.97 & 3.10 & 9.95 & $0.985(0.980-0.989)$ & 0.985 \\
\hline Intermittent pain subscale & 10.00 & 22.22 & 3.74 & 11.04 & $0.963(0.950-0.974)$ & 0.963 \\
\hline KOOS & 48.40 & 28.11 & & & & \\
\hline \multicolumn{7}{|l|}{ Validity } \\
\hline & \multicolumn{2}{|c|}{ Constant pain subscale } & \multicolumn{2}{|c|}{ Intermittent pain subscale } & \multicolumn{2}{|l|}{ Total score } \\
\hline & $r$ & P-value & $r$ & P-value & $r$ & P-value \\
\hline KOOS & 0.324 & 0.086 & 0.025 & 0.896 & 0.235 & 0.221 \\
\hline
\end{tabular}


The ICC of the original scale was 0.93, whereas the ICC of the Portuguese scale was 0.88-0.92, and the Persian result was 0.91 [14-16].

The construct validity of the ICOAP-AR scale and the KOOS pain subscale of $r=0.24(P<0.05)$ represents a good correlation between the knee ICOAP-AR and the KOOS, while the correlation in the original study was $r=0.6$. The modest correlation between the two scales is due to the nature of the ICOAP scale, which evaluates the patient's condition based on the severity of the pain. On the other hand, the KOOS questionnaire identifies the participant's physical symptoms, such as swelling, stiffness, and pain in the knee joint $[13,17]$.

\section{Conclusion}

The psychometric evidence supports the Arabic version of the ICOAP as a reliable and valid cross-sectional measure of the impact of intermittent and constant pain in patients diagnosed with knee or hip osteoarthritis.

\section{Acknowledgements}

We thank all the participants in our study. Also, we thank Omar Alsultan for helping us in the translation of the Questionnaire.

\section{Conflict of Interest}

The authors declare that they have no conflict of interest.

\section{References}

[1] National Collaborating Centre for Chronic Conditions N-C Osteoarthritis: National clinical guideline for care and management in adults. London: Royal College of Physicians; 2008

[2] Røgind H, Bibow-Nielsen B, Jensen B, Møller HC, Frimodt-Møller H, Bliddal $H$. The effects of a physical training program on pat with osteoarthritis of the knees. Arch Phys Med Rehabil 1998; 79: $1421-1427$

[3] Neogi T. The epidemiology and impact of pain in osteoarthritis. Osteoarthritis Cartilage 2013; 21: 1145-1153

[4] Dillon CF, Rasch EK, Gu Q, Hirsch R. Prevalence of knee osteoarthritis in the United States: Arthritis data from the Third National Health and Nutrition Examination Survey 1991-94. J Rheumatol 2006; 33: 2271-2279

[5] Srikanth VK, Fryer JL, Zhai G, Winzenberg TM, Hosmer D, Jones G. A meta-analysis of sex differences prevalence, incidence and severity of osteoarthritis. Osteoarthritis Cartilage 2005; 13: 769-781
[6] Lohmander LS, De Verdier MG, Rollof J, Nilsson PM, Engström G. Incidence of severe knee and hip osteoarthritis in relation to different measures of body mass: A population-based prospective cohort study. Ann Rheum Dis 2009; 68: 490-496

[7] Wilder FV, Hall B], Barrett JP, Lemrow NB. History of acute knee injury and osteoarthritis of the knee: A prospective epidemiological assessment. The clearwater osteoarthritis study. Osteoarthritis Cartilage 2002; 10: 611-616

[8] Zhang W, Doherty M, Peat G, Bierma-Zeinstra SMA, Arden NK, Bresnihan B et al. EULAR evidence-based recommendations for the diagnosis of knee osteoarthritis. Ann Rheum Dis 2010; 69: 483-489

[9] Hawker GA, Davis AM, French MR, Cibere J, Jordan JM, March L et al. Development and preliminary psychometric testing of a new OA pain measure - an OARSI/OMERACT initiative. Osteoarthritis Cartilage 2008; 16: 409-414

[10] Zhang C, Liu DH, Qu YL, Jia ZY, Wang W, Li J et al. Transcultural adaptation and validation of the Chinese version of the intermittent and constant osteoarthritis pain (ICOAP) measure in patients with knee osteoarthritis. Osteoarthritis Cartilage 2017; 25: 506-512

[11] Manolarakis GE, Kontodimopoulos N, Sifaki-Pistolla D, Niakas D. Establishing the psychometric properties of the ICOAP questionnaire through intra-articular treatment of osteoarthritic pain: Implementation for the Greek version. 2016, doi:10.1155/2016/6201802

[12] Favero M, Ramonda R, Goldring MB, Goldring SR, Punzi L. Early knee osteoarthritis. RMD Open 2015, doi:10.1136/rmdopen-2015-000062

[13] Maillefert JF, Kloppenburg M, Fernandes L, Punzi L, Günther KP, Martin Mola E et al. Multi-language translation and cross-cultural adaptation of the OARSI/OMERACT measure of intermittent and constant osteoarthritis pain (ICOAP). Osteoarthritis Cartilage 2009; 17: 1293-1296

[14] Panah S, Baharlouie H, Rezaeian Z, Hawker G. Cross-cultural adaptation and validation of the Persian version of the Intermittent and Constant Osteoarthritis Pain Measure for the knee. Iran J Nurs Midwifery Res 2016; 21: 417-423

[15] Gonçalves RS, Cabri J, Pinheiro JP, Ferreira PL, Gil J. Cross-cultural adaptation and validation of the Portuguese version of the intermittent and constant osteoarthritis pain (ICOAP) measure for the knee. Osteoarthritis Cartilage 2010; 18: 1058-1061

[16] Erel S, Şimşek IE, Özkan H. Analysis of the reliability and validity of the Turkish version of the intermittent and constant osteoarthritis pain questionnaire. Acta Orthop Traumatol Turc 2015; 49: 508-512

[17] Roos EM, Roos HP, Lohmander LS, Ekdahl C, Beynnon BD. Knee Injury and Osteoarthritis Outcome Score (KOOS)-development of a self-administered outcome measure. J Orthop Sport. Phys Ther 1998; 28: 88-96

[18] Harriss DJ, MacSween A, Atkinson G. Standards for ethics in sport and exercise science research: 2018 update. Int J sports Med 2017; 38: $1126-1131$ 